\title{
Kırmızı Pelerinli Kent Kitabının İngilizceye Çevirisinin Çeviri Kuramında Toplumsal Cinsiyet ve Yeniden Yazma Ekseninde Bir Değerlendirmesi
}

\author{
An Evaluation of the English Translation of 'The City in Crimson Cloak' \\ Through The Concepts of Gender and Rewriting in Translation Theory
}

\section{Göksenin ABDAL*}

Öz: Bir kadın yazar olarak, Aslı Erdoğan, anlatılarını dünyanın kurulu düzenine karşı dirençle ayakta kalma isteğiyle kurgular. Kırmızı Pelerinli Kent'te ana izleği oluşturan kent imgesi, Rio şehrinde vücut bulur. Kitabın başkahramanı Özgür, zıtlıkların ortasında çareyi bir 'kırmızı pelerinli kent' kitabı yazmakta bulmuştur. Metnin kadın çevirmeni Amy Marie Spangler metni toplumsal cinsiyet eşitliği temelli bir çeviri yaklaşımıyla yeniden yazma girişimi olarak ele alır. Bu çalışma içerisinde, Aslı Erdoğan'ın Kırmızı Pelerinli Kent kitabının çevirisi The City in Crimson Cloak kitabı, metnin Amerikalı çevirmeni Amy Marie Spangler'ın Rio de Janeiro'da geçen Türkçe bir öyküyü çevirme motivasyonu çerçevesinde çözümlenmiştir. Çalışmanın amacı hem çevirmenin hem de yazarın kişiliklerinden izler taşıyan çeviri metindeki kültüre bağlı ve toplumsal cinsiyet temalı çeviri kararlarının izini sürmektir. Çalışmanın ilk bölümünde, Aslı Erdoğan'ın üslubu ve kitaplarında kullandığı temalar okur bakış açısı üzerinden ele alınmıştır. İkinci kısımda, kaynak metin Kırmızı Pelerinli Kent kitabındaki kültürel öğeler üzerinden öykünün ana hattı çizilmiş; üçüncü kısımda, çevirmenin aldığı kararlar, önceki bölümde bahsedilen kültürel öğeler de göz önünde tutularak, kültürel çeviri kuramında toplumsal cinsiyet ve yeniden yazma kavramları ışığında değerlendirilmiştir. Yapılan incelemeler ve değerlendirmeler sonucunda, çevirmenin kültürel sınırları yansıtma, dilsel gelenekleri birleştirme ve çevirinin uzamını genişletme girişimleriyle metnin çeviri versiyonunun kültürel anlamda bir melez metine dönüştüğü fark edilmiştir.

Anahtar sözcükler: Toplumsal Cinsiyet, Edebiyat Çevirisi, Cinsiyete Dayalı Çeviri, Yeniden Yazma, Kültürel Çeviri Kuramı

\begin{abstract}
As a woman writer, Aslı Erdoğan has been able to produce many works through her resistance against the established order of the world. The image of the city, the main theme of The City in Crimson Cloak, comes into body in the city of Rio. The book's main character Özgür resorts to writing her version of "The City in Crimson Cloak". The female translator of the text, Amy Marie Spangler, surveys the text with an attempt to rewrite it through a gender equality based approach. In this paper, the translation of her book is analyzed through an American translator's motive to translate a Turkish story taking place in Rio. The aim is to trace the culture and gender related decisions in the translated text which seems to bear features of personalities of both the translator and the author. In the first part of the paper, Aslı Erdoğan's writing style and themes in her books are surveyed from a native readers perspective. In the second part, main line of the story is drawn upon cultural elements in the source text. In the third part, the decisions made by the translator are studied via the cultural elements in the previous part under the concepts of gender and rewriting in cultural translation theory. After the process of analysis, it was realized that the translated version of the text became a culturally hybridized text with the translator's attempt towards reflecting cultural boundaries, combining linguistic traditions and broadening the perspective of translation.
\end{abstract}

Keywords: Gender, Literary Translation, Gender Translation, Rewriting, Cultural Translation Theory

\footnotetext{
* Arş. Gör., İstanbul Ünivesitesi, Edebiyat Fakültesi, Çeviribilim Bölümü, İngilizce Mütercim Tercümanlık Anabilim Dalı, İstanbul. abdalgoksenin@gmail.com
} 


\section{Giriş}

Aslı Erdoğan, hem yazdıklarıyla hem de yaşadıklarıyla Türk edebiyat camiasında oldukça fazla kez gündeme gelmiştir. Çok kez eleştiriyle karşılaşmış olsa da Aslı Erdoğan, yazmayı asla elden bırakmamıştır; bırakmaya pek de niyetli görünmemektedir. Yazdıklarında ses vermeye çalıştığ kadınlık deneyimi ve dünyaya dair algısı, temel mesele olarak kahramanların yaşadıkları aracılığıyla okura sezdirilir. Aslı Erdoğan, anlatılarının söylemini, dünyadaki kurulu düzene olan karşıtllı̆g 1 ve kimseye benzemek zorunda kalmadan bir arada kalmak özlemiyle kurgular.

Aslı Erdoğan'ı özel kılan şey, kendi benliğine dair sorun ve duyarlıklarını kahramanlarının ağzından, yine kahramanlarının seçtiği sözcüklere kendi içre anlamlar yükleyerek anlatmasıdır. Aslı Erdoğan, hayatı boyunca karşısına çıkmış insanları birer karakter olarak kitaplarına yansıtmakla kalmaz, aynı anda bu karakterleri kendisiyle kurdukları ilişkiler bağlamında farklı katmanlarda yeniden kurgular ve onlara toplumsal hayatta sürekli karşılaştığımız, alıştığımız birer görünüm kazandırır. Onun kitaplarındaki karakterler, sokakta dikkat çekmeden yürümeyi başaran, kendi hallerinde kendilerini gerçekleştirmeyi umut eden karakterlerdir. Söz konusu umut hissi, okurların, sayfa aralarında takip ettiği ve elini tutmaya çalıştığ "eşit»" kahramanlarda kendilerinden parçalar bulmasına olanak sağlar. Kurduğu dilsel anlatım ve imgeler evreni; korku, duyarlık, kırılganlık, cesaret, direnme, harekete geçme, bütün olumsuzluklara rağmen kendini var etme ve sesini yükseltme gibi duygularının yansımaları olarak yazarın eserlerinde kendine yer edinir. Her karakter, özellikle de başkarakter olan kadınlar, kurulu düzenin dışına çıkmayı marjinal sayan toplumsal hayat kurallarını hiçe sayarak ve her türlü baskı mekanizmasını reddederek kadınca var olmaya devam eder. Aslı Erdoğan da Türkiye toplumu için bu kadınlardan biri sayılabilir. Yazar, kadınların zihinsel deneyimlerinden ve fiziksel güçlerinden yararlanmayı kendine bir borç bilir ve kadınlık deneyimini şiddetle mücadele ekseninde biçimlenmiş bir yaşamsal arayış olarak eserlerinin ana izleğine yerleştirir.

Türk edebiyatının ayrıksı ve modernin ötesindeki sesi olarak Aslı Erdoğan, yalnızlıklarıyla yaşamaya alışan veya bunu öğrenmeye zorlanan karakterler ve kurmaca dünyasına ait yükleri taşımaya çabalayan bu karakterlerin giderek yalnızlaştırıldığı yanılsatıcı dekorlar bütünü yoluyla, sözsel, duyumsal ve görsel metin parçalarını yaşanmışlıklar olarak okurların gözleri önüne serer. Kurmaca yaşam, temelini gerçeklerden alıyor gibi görünse de, her öyküde farklı bir izlekle okurlara sunulur. Bu izlek, kimi zaman bir dil uzmanının tahtaya not almak için kullandığı tahta kalemleri kimi zaman da tropik bir adaya hapsedilmenin verdiği çaresizlik ile güçlü hayatta kalma güdüsü çevresinde kurgulanır.

Bu çalışmanın amacı, farklı kültürel ve toplumsal bağlamlarda bir toplumsal cinsiyet kategorisi olarak kadınların yaşam deneyimlerini merkez alarak; çeviride yeniden yazma yaklaşımını Aslı Erdoğan'ın Kırmızı Pelerinli Kent kitabı üzerinden ele almaktır. Bu bağlamda, ayrıca, kültürlerarası iletişim ve aktarım temelinde çeviri, toplumsal cinsiyet ve yorumlama kavramları arasındaki bağlantıları ortaya koymak hedeflenmektedir. Birinci bölümde, Aslı Erdoğan'ın edebi kişiliğine ve yapıtlarında kullandığı temalara dair bilgiler verilecek; ikinci bölümde, bu çalışmanın temel inceleme kısmını oluşturan Kırmızı Pelerinli Kent kitabında toplumsal cinsiyet kavramı üzerinden yazarın oluşturduğu anlatı öğelerine dair genel bir çerçeve sunulacak; son kısımda ise kitabın İngilizceye çevirisi, çeviri kuramındaki yeniden yazma ve toplumsal cinsiyet kavramlarından yola çıkılarak değerlendirilecektir. 


\section{Bir “Öteki” Yazar Olarak Aslı Erdoğan'ın Edebi Kişiliği ve Eserlerindeki Temalar}

1967 yılında İstanbul'da doğan Aslı Erdoğan, Boğaziçi Üniversitesi’nde Bilgisayar Mühendisliği eğitimi aldı (Ayrıntılı bilgi için bk. www.aslierdogan.com). Ardından CERN'de (Avrupa Yüksek Enerji Fiziği Laboratuvarı) yüksek lisans eğitimini tamamladı. Fizik doktorası için gittiği Rio de Janeiro'da eğitimini yarıda bıraktı ve yazmaya yöneldi. İlk romanı Kabuk Adam 1994'te, öykü kitabı olarak yayına hazırlanan Mucizevi Mandarin 1996'da yayınlandı. Birçok dile çevrilen Tahta Kuşlar öyküsü, Deutsche Welle Ödülü'ne layık görüldü (Unionsverlag n.d.). 1998'de yayınlanan ikinci romanı Kırmızı Pelerinli Kent; Fransızca, İngilizce, Almanca ve Norveççe olmak üzere birçok dile çevrildi ve Gyldendal Yayınları tarafindan, yazınsal açıdan dünya edebiyatına yenilik getiren eserlerin listelendiği Marg (omurilik) serisine dâhil edildi (Savaş 2004). 2000 yılında Bir Yolculuk Ne Zaman Biter, 2005'te Hayatın Sessizliğinde adlı kitapları yayınlandı. Gazete yazıları ve denemeleri, Bir Delinin Güncesi ve Bir Kez Daha adlarıyla 2006 yılında kitaplaştırıldı. Yazdıkları birçok farklı dile çevrilen Erdoğan, Fransız kültür sanat ve edebiyat dergisi Lire tarafından "Geleceğin 50 Yazarı" arasında gösterildi (Payot 2014). Son kitabı Taş Bina ve Diğerleri, 2009 yılında okurla buluştu. Yazarın Yunus Nadi Ödülleri'nde üçüncülüğü (Cumhuriyet 1990) ve Sait Faik Öykü Armağanı'nda birinciliği bulunmaktadır (Unionsverlag 2010). Erdoğan, 2011'de Lillehammer Festivali'nin açılış konuşmasını yapmış (Verissimo 2011), 2012'de Zürih Şehir Yazarı seçilmiş (writers-in-residence 2012) ve 2013’te Ord i Grenseland Prisen - Sınırda Sözcükler Ödülü'nü kazanmıştır (Forfatterforening 2013). Son olarak, 2016 yılı Eylül ayında, İsveç Pen tarafından Tucholsky Ödülü’ne layık görülmüştür (Svenskapen 2016).

Aslı Erdoğan'ın, geçmiş ve şimdiki zaman arasında bağ kuran, geçmiş zamandaki kadınlık deneyimlerinin şimdiki zamanda alınan kararlar üzerindeki etkilerini sorgulayan bir yazar olduğu söylenebilir. Yazar eserlerinde anlık görüntüleri ve geçmiş zamanı çağrıştıran imgeleri bir saç tokası, bir vazo süsü, bir cam kırığı, sarı bir yaprak - kullanmayı ve bu imgeleri okura hatırlatmayı sever. Örneğin, öykünün bir tarafında yerde cam kırıkları olduğunu okuyan okura, daha önceki sayfalarda anlatılan cam vazo öyküsüyle esasında cam vazonun bir olay sonucunda parçalandığı sezdirilir, ancak neyin sonucunda böyle bir şey olduğu ya ilerleyen sayfalarda anlatılır ya da okurun zihninde böyle bir soruyla kitabı bitirmesi beklenir. Böylece anlatılan şey, Aslı Erdoğan'a ait olmaktan çıkar ve tıpkı kadın bedeninin toplumsal bir meta olarak kabul edilmesi gibi, kamusallık ve anonim olmakla bağdaştırılır (İmşir 2012, 42).

Aslı Erdoğan'ın en önemli yönü, anlattığı öykülerdeki boşlukları doldurma işini okura bırakmasıdır. Aslı Erdoğan, kalemini bir fırça gibi kullanıp, gördüklerine ve yaşadıklarına dokunarak bazen rengârenk, bazen siyah-beyaz ve gri tonlu tablolar çizse de, nesnelere verilen değer, öykü kurgusunun belirli nesneler çevresinde şekillenmesiyle kendini belli eder. Bu aşamada renklerden ziyade sözcükler ve anlatılar devreye girer. Bütün nesnelerin ortasında kalan birey için kaçınılmaz son yabancılaşmadır. Aslı Erdoğan, kendi hayat yolculuğunda da eserlerinde anlattıklarıyla benzerlik gösteren deneyimler yaşamıştır. Aslı Erdoğan, ebeveynlerinin farklı kökenlerden gelmesi dolayısıyla, ailesinin parçalanış sürecinde sürgün olma hissini yaşamış, bu his de onu ebedi bir yolcu ve sürgün olduğuna inandırmış ve terk etmek ve durmak hisleri arasındaki ikilemi sürekli olarak yaşamak zorunda bırakmıştır (Karaca 2012, 165).

Aslı Erdoğan'ın anlatılarında genellikle başkişi konumundaki kadın anlatı kahramanlarının yüzleştiği yabancılaşma, kahramanların hem kendi toplumlarına karşı hem de çeşitli nedenlerle bulundukları yabancı ülkelere karşı herhangi bir aidiyet duygusu geliştirememeleriyle öne çıkar (Özger et al. 2012, 2564). Etrafındaki nesnelere, insanlara, doğaya, binalara ve kente yabancılaşmaları kahramanların kendi içlerine dönmesini de kaçınılmaz kılar. İçe dönüşten itibaren 
kahramanlar, dış dünyadaki olayları yalnız kendi iç dünyalarındaki duygulanımlarla eş zamanlı olarak algılamaya başlarlar. Kahramanların kadın bedenleriyle hem kaçış hem de sığınma duyguları üzerinden geliştirdiği bu ikircikli ilişki, Aslı Erdoğan kurmacasının merkezinde iç çekişlerle ve hızla akıp giden monologlarla okurun dikkatini çeker (İmşir 2012, 50).

Aslı Erdoğan'ın anlatılarında karşımıza çıkan başka bir özellik ise kahramanların yalnızlık duygusuna kapılarak dünyevi gerçeklikten kopmalarıdır. Onlar için tek gerçeklik, kadın olma halinin toplumsal düzlemde yarattığı gelgitlerin iç dünyaya sığınarak yahut bulunulan yerden tamamen uzaklaşarak dengelenmeye çalışılmasıdır. Kahramanlar gerçeklikle düşsellik düzlemleri arasında kapana kısılmıştır; ya gerçek dünyada karanlık sulara gömüleceklerdir ya da düşler diyarında 1şıkta boğulacaklardır (Karaca 2012, 161). Yaşadıkları şeyleri anlık bir yanılsamadan ibaret olarak gören kadın öykü ve roman kahramanları, Erdoğan'ın kaleminin ucunda birer kuklaya dönerler. Hem yazarın hem de yaşadıklarının rüzgârıyla olay kurgusu içerisinde bir oraya bir buraya savrulurlar. Bu savrulmayla beraber bir çaresizlik ve yalnızlık hissine mahkûm olurlar. Bu savrulmalar yalnızca fiziksel yaraları değil, ruhsal yaraları da beraberinde getirir; bunun sonucunda, sürekli olarak toplumsal hayatın merkezinden çevresine hareket etme eğilimi gösteren kahramanlar, toplumun ötekileştirdiği kişiler olarak suç işleme eğilimi gösterir ve kendilerini hem suçlu hem de kurbanlar olarak okura sunarlar (İmşir 2012, 57). Aslı Erdoğan'ın kahramanları, dünyayı kimsenin kendilerine yardım edemeyeceği ve mutlak anlamda yalnız oldukları bir yer olarak algılarlar, içinde oldukları ruh halinin etkisiyle de toplumdan ve çevreden uzaklaşarak kendi iç dünyalarına çekilirler (Özger et al. 2012, 2567). Suçluluk hali ve kurban olarak hissedilen mağduriyet, kahramanlar olarak kadınların dünya ile kurdukları zayıf bağlarla açıklanabilir.

Yazarın romanlarında kahramanı oluşturan diğer bir öğe ise hiçliktir. Önce etrafındaki toplumla bağlarını koparan, sonra ise kendi içine kapanan kadın anlatı kahramanları, zamanla kendilerine de yabancılaşarak hiçliğin ortasında kalırlar. Anlatılarda düşler dünyasında yaratılan birtakım şeyler, gün doğumu gibi başka bir olayın yaşanmasıyla birlikte kahramanların yabancılaştı̆̆ı, kopma yaşadıkları dış mekâna/hiçliğe dönüşür. Sonraki aşamada yabancılaşmanın kendisi de dâhil olmak üzere yalnızlık ve diğer tüm hisler, havaya karışır ve yok olur (Karaca 2012, 163). Yabancı bir yerde, yabancı insanlarla çevrili olarak, yabancı nesnelere dokunarak, bakarak yaşamak gerçeğiyle yüzleşmek kahramanları hiçliğin ortasına bırakır. Anlatılarda kişiler, hayatın anlamını sorgulamaya başlar; derin sorgulamalardan sonra evren üzerindeki varlıklarının anlamsız, yapılacak her şeyin ise boşuna olduğu duygusuyla baş başa kalırlar, bunun sonucunda hayatın tüm renkleri solar, gri bir tablo oluşur (Özger et al. 2012, 2569). Tıpkı Aslı Erdoğan'ın kendi kişiliği gibi, kahramanlar da topluma zayıf bağlarla bağlı kalır, ancak farklılığa ilişkin bütün kopuş duygularına inat toplumsal yaralardan uzaklaşma davranışı göstermezler. Bunun tam tersine, kadınlara dair toplumsal cinsiyet algısından ötürü toplumsal düzende aşağ konumda yer aldıkları, hayatları boyunca her an kendilerine hissettirilmesine rağmen, aksaklıkların ve sorunların üzerine gitme, çözüm önerileri bulma çabası içindedirler. Her yazınsal eserin bitiminde, toplumsal gerçeklerin ötesine geçebilen azizelere dönüştükleri fark edilir.

\section{İnsan Doğasının Çeşitliliğgiyle Parçalanan Bir Esrik Dünya: Kırmızı Pelerinli Kent}

Aslı Erdoğan'ın ilk kez 1998 yılında yayınlanan Kırmızı Pelerinli Kent adlı kitabı basıldığı dönemde yalnız Türkiye'de değil, aynı zamanda Avrupa'da da büyük yankı uyandırmıştır. Sırasıyla Fransızca, İngilizce ve Almancaya çevrilen kitap (Erdoğan 2003; 2007; 2008), uzak bir ülkede hayatta kalma mücadelesi veren bir öykü kahramanının yaşama tutunma mücadelesini anlatır.

Aslı Erdoğan, Türkiye'de başladığı hayat yolculuğunu Rio'nun “tehlikeli” varoş mahallele- 
rinde sürdürdüğü dönemde bir seyyah olarak ilk yeğni adımlarını atarken, özgürlük hissini de korkunun egemen olduğu, şiddetin kanlı yüzünü gösterdiği başka bir dünyanın dar sokaklarında tedirginlikle değiş tokuş eder. Her ne kadar özgürlük aramak için yola çıkmış olsa da kendisini ülkesinden daha derin ve kendi deyimiyle egzotik bir kaos ormanının ortasında bulmuştur. Kırmızı Pelerinli Kent'te, Aslı Erdoğan'ın uzaklarda hissettiklerinden ismini alan ana karakter olan Özgür'ün etrafı, basit şeylerle mutlu olmasını bilen, küçük kibrit çöplerinden okyanus büyüklüğünde mutluluklar yaratabilen mutlu kadınlarla çevrilidir. İnsanların hayatlarından karnaval, sihir eksik olmaz (Bağcı 2010, 10). Rio'da yoksulluk oranı, çocukların suça olan eğilimi yüksek olmasına ve sosyal koşullar daha zorlu olmasına rağmen, insanlar mutludur. Üzerlerinde toplumsal baskılar olmak bir yana dursun, kadınlar, toplumsal hayatın her alanında gözlerle yargılanma korkusu olmaksızın kendilerinden emin adımlar atmaya devam ederler.

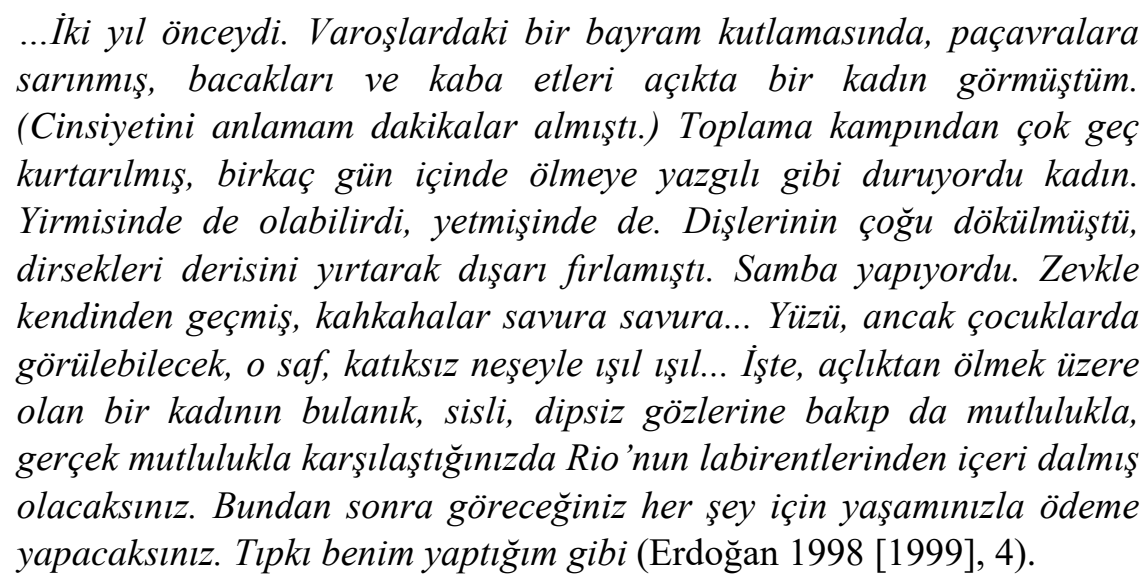

Erdoğan, kitap içerisinde bir başkahraman olarak yarattığı, adını ilham kaynağı ve kaçış amacı olan özgürlükten alan Özgür karakteri yardımıyla, okurun gözünde eserin arka planını oluşturan dünyaya dair manzarayı anlatan bir tablo çizmeyi başarır. Çizdiği tablonun ortasına da okuru bırakır. Yalnız ve mutsuz olarak yaşamaya ve kadınca içgüdüleriyle var olmaya çalışır (Özger et al. 2012, 2567). Yoksul arka sokaklarına kıyıdaki güneşli gökdelenlerin gölgelerinin düştüğü baharat kokulu kent içerisinde, Özgür, yabancılaşmayı simgeleyen bir kadın ruh olarak terk edilmiştir.
...Önünde kara tüneller gibi uzanan gecelerle başa çıkamadı̆̆ için, en yoğun acıların merhemi insan gövdelerine sarılmış; çelimsiz cinselliği- nin bir doğuştan sambacıdan ötekine şutlanmasina uysallıkla boyun ĕgmişti. Aşk öykülerinde konu mankeni olduğunun ayırdına varmıştı var- masına; ama yalnızlıktan öyle şaşkına dönmüştü ki, en çıkarcı ilişkilerde bile bulunan titrek, krrlgan sevgi soluğuyla yetinmeye hazırdı (Erdoğan 1998 [1999], 66-67).

Kıyıdaki geniş bulvarlarda dizilen sokaklar ne kadar aydınlık ve zenginse, iç kısımlardaki sokaklar da o denli karanlık ve tuzaklarla doludur. Yazar, Özgür'ü kentin ortasına terk etmekle yalnızca yuvadan kaçışının değil, aynı zamanda kendi yabancılaşma deneyiminin de katmanlı olarak kapılarını aralar. Aralanan kapıların ardında görünen yer yazarın uçaktan iniş anından evinin kapısını açana kadar şahit olduğu şehrin görüntüsüdür. Kente verdiği isim, kaçarken hissettiklerin birebir yansımasıdır: Özgürlük ve kayboluş arasındaki tekinsiz yürüyüş (Armağan 2013, 34). Özgür, yalnızca başka bir dilde, başka bir kültürde büyümüş, yaşamış, eğitim almış bir birey olarak değil, aynı zamanda farklı fiziksel ve ruhsal özelliklere sahip olan bir kadın ola- 
rak yabancıllğğı hisseder:

...Sonunda, çevresini kuşatan boşluğa anlam katabilecek tek kişinin kendisi olduğunu anladı. Başka hiç kimse onun adına yaşamın şifrelerini çözemez, asma kilitlerini açamazdl. Kentin gözü kör şiddetine karşı mevzilerini belirlemeye karar verdiği gün yazmaya başladı. Ne başkaları, ne de kendisi için; sadece yazmak zorunda olduğu için yazıyordu. Bir yarayı kaşırcasına kabuk kabuk soyuyordu Rio gerçeğini ve iç kanamalı bir hastanın kustuğu kara kan, cümlelerine damliyordu (Erdoğan 1998 [1999], 68).

Yazarın gördükleriyle hissettikleri aynı çarkta iç içe geçerek farklı anlatıcıların olduğu bir eser kurgusunu meydana getirir. Bu aynı zamanda kimliksizliğin de göstergesidir. Ö. karakteri üzerinden anlatmaya başladığı ikinci öykü, iç hesaplaşmayı gerçekleştirmesi açısından öykünün ikinci izleğini oluşturur (Armağan 2013, 38). Özgür, kimliksizleştikçe kafasının içerisinde ona seslenen sesler çoğalır, zihnini meşgul eder, bütün sorunlar arasında kentteki varoluşunu gerçekleştirmek ve güçlenmek için içindeki gücü, kadınlığını daha fazla duymaya ve kökleriyle yeniden bağ kurmaya, geride bıraktıklarını yeniden anımsamaya başlar.

...Imgelemin plasentasında donup kalmış anıların üzerine bir kat şiirsellik cilası çekmekti amacı. Oysa apayrı bir öykü çıkmıştı ortaya; Özgür'ün "başından geçse de" gerçekte onun "yaşamadı̆̆g," bir başka kadına, Ö. ye ait bir öykü. Karnındaki bebeğin tekmelerini dinleyen bir anne gibi geliş̧imini izlediği, her geçen gün bağımsızlaşan bu dik başlı kadın, yazardan sürekli rol çallyor; büyük harflerle yazılmış dramlarda odak noktasını kapıyordu. Özgür'ün renksiz ruhu bir prizmadan geçirilmişçesine, ışık tayfinın bütün renklerine kavuşmuştu Ö. de (Erdoğan 1998 [1999], 77).

Özgür'ün gördükleri, gördükleri karşısında hissettikleri, hissederken aklından geçirdikleri, düşünürken söyledikleri birbirlerini sarıp sarmalayan bir dil evreni çevresinde okura aktarılır. Özgür'ün gözleriyle çevresindekileri süzmeye çalışan okur, hem görür hem hisseder hem düşünür hem de olaylar arasındaki bağlantıyı çözmeye çalışır. Kırmızı Pelerinli Kent'te kendi içre bir Ö. karakteri yaratan Özgür’ün, baktığı her yerde başka türlü biçimlerde tanıklık ettiği şiddet biçimlerini alımlamaya çabalarken zorlandığını yazmakta bir bahis görmediği anlaşılabilir (Bağc1 2010, 10). Bir kadın olarak yazmak ve toplumsal hayatın mekanizmalarının normatif bask1 odaklarından sıyrılarak kendini ifade etmek, bu dil evreninin en önemli bileşenlerinden biri olarak görülebilir.

...Derin bir soluk alarak kalemi masaya bıraktı. Gözleri, hala yeşil kaplı defterdeydi, kendi geçmişine takılıp kalmıştı. Romanını bitirmişti. Dünyaya söylemek istediği herhangi bir söz kalmamıştı artık. Bir uçtan ötekine kendi cehennemini anlatmıştı işte. Bütün yolların aynı kör noktaya açıldi ̆̆g gerçeklik labirentinde son durağa varmıştı. İşkenceden geçmiş, yarl yartya erimiş gibi hissediyordu kendini; ama aynı zamanda, bir şekilde büyümüştü de. Yıkım sürecinin dışına çıkmış; onu, diri diri ambere gömülen bir sinek gibi, kaskatı sinırlar içinde sonsuza dek yakalamıştı. İstediği an hayranlıkla seyredebileceği bir nesneye dönüştürmüştü (Erdoğan 1998 [1999], 124).

Aslı Erdoğan, yukarıda anlattığım kurgusal düzlemi gerçekleştiren dilsel yapıyı sözcük tekrar- 
ları, tamlamalar, betimlemeler, kesintili cümleler, yerel söyleyişe özgü deyim kullanımları, yabancı sözcükler, yabancı yer isimleri kullanarak gerçekleştirir. Sözcüklerin sık sık tekrarlanması, sonraki bölümlerde önceki bölümlerdeki sözcükleri hatırlatan ama başka çağrışımlar yaratan sözcüklerin kullanılması, eş sesli sözcük kullanımlarına yoğun olarak yer verilmesi metnin dilsel zenginliğini artırmakla kalmaz, aynı zamanda Aslı Erdoğan'ın yazarlık deneyimine dair de bilgiler sunar. Aslı Erdoğan, anlatının olanaklarından yararlanarak dilin sınırlarında gezinmeyi alışkanlık haline getirmiş olsa da günlük konuşma diline yakın sözcükler tercih etmesi metnin inandırıcılığını ve gerçekliğini artırır. Buna bağlı olarak, okurun, metnin yazarının anlattığı dünyadaki karakterlerle özdeşlik kurma olanağı artar. Bu sayede, metin okumalık bir metin olmaktan çıkar ve okurun kendi yaşamından izler bulabileceği ve özdeşlikler kurabileceği bir metin haline gelir:

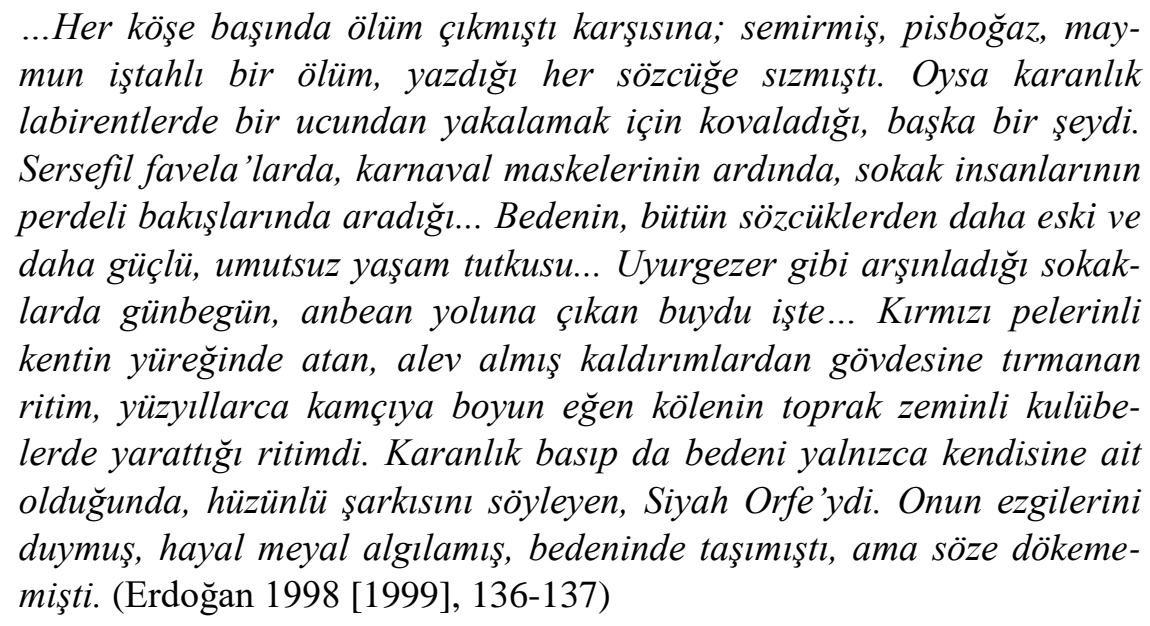

Kırmızı Pelerinli Kent'in Dar Sokaklarında Bir Çevirmenin Yeniden Yazma Deneyimi

Aslı Erdoğan, nasıl ki Özgür aracılığıyla kentin kendisine ve orada karşılaştığı her şeye - parklardaki insanlara, heykellere, köşe başlarındaki fahişelere, transseksüellere, kilise duvarlarına, meydanlardaki çeşmelere ve kent imgesini oluşturan diğer her şeye - kendini uzak hissediyorsa ve duygu yoğunluğundan ötürü bu uzaklık hissini okura aktarırken tamlamaları ardı ardına sıralıyorsa, çevirmen de aynı duygusal yoğunluğu hissetmeye, aynı etkileri yaratmaya çalışır. Ancak bu sefer her iki kültüre dair farkındalığını kullanarak bir tür yorumlama pratiği gerçekleştirir. Yazma süreci bakımından, yazar ve çevirmen arasında önemli bir fark vardır: Metnin yazarı, kalbinde taşıdığı Türkiye izleğini kullanarak Brezilya'yı yaşamaya çalışır; metnin çevirmeni, Türkiye kültürünün bir "yabancısı" ve "sonradan tanıyanı" olarak hem yazarın doğduğu, büyüdüğü ülkedeki yaşantısını bilmek hem de yazarın Brezilya'daki şahitliğini kendi köklerinden gelen ön kabulleri katmadan aktarmak durumundadır. Burada da çevirmen olmanın getirdiği ikilem ortaya çıkar: Öznel alımlama becerisine dayanarak yazarın söyleyişini çevirmek.

Çeviri sürecinde çevirmenin kendi kültür dizgesiyle kurduğu bağlardan kopmayarak kaynak kültür dizgesindeki metni yeniden yazma girişiminde bulunduğu öne sürülebilir. Çevirmen, yorumlama pratiğini gerçekleştirirken kendi kültürel arka planından getirdiği deneyimlerini de kullanır ve erek metni yaratırken yorumlamaya dayalı bir yeniden yazma pratiği geliştirir. Kırmızı Pelerinli Kent söz konusu olduğunda, metnin çevirmeni, Amy Spangler'in, metnin yazarı gibi, kadınlık deneyimleri üzerine düşünen ve kendisini bir kadın olarak gerçekleştirmeyi önemseyen bir birey olarak konumlanması, toplumsal cinsiyet algısı bakımından yazarla çevirmen arasında anlayış ve bakış açısı benzerliğini kaçınılmaz kılar. Çevirinin, sözcüklerin erek metin içinde yan yana koyularak erek dil ekseninde bağlamsallaştırıldığı bir yeniden yorumlama 
ve yorumlayarak yazma pratiği olduğu düşünüldügünde, imgelerin kişiden kişiye değişme olas1lığı, çevirmenin çeviri sürecine kendi algı dünyasına göre yön verdiği izlenimini yaratır.

Yeniden yazma yaklaşımının da dayandığı, göstergelerin oluşturduğu dil dizgesi kavramından başlayıp bağlama doğru ilerleyen çeviri anlayışı, kültürel öğelerin ve toplumsal izleklerin etkisinde kalan ve buna uygun bir bağlam yaratma çabasında bulunan çevirmeni merkeze koyar. Bassnett ve Lefevere $(1998,66)$, çeviri sürecinin süreç üzerinde etkisi olan erk ve iktidar ilişkilerinden bağımsız düşünülemeyeceğini, günün koşullarının çeviri sürecine birebir etki ettiğini, çünkü çevirmenin toplumsal koşullardan bağımsız bir yere konumlanmasının mümkün olamayacağını belirtir. Kadın olmanın öteki olmakla birebir tutulabileceği erek zaman ve mekânlarda, kadın çevirmen Amy Spangler'in erek dil ve metin bağlamında kaynak metnin amaçladığı iletinin içeriğindekinden daha keskin, daha sert sözcük ve tamlamalar seçmesi olağan bir durum olarak görülebilir.

\begin{tabular}{|c|c|c|}
\hline $\begin{array}{l}\text {...Aynı karanlık, mezar gibi } \\
\text { gözler,... } \\
\text { (Kırmızı Pelerinli Kent, s. 97) }\end{array}$ & $\begin{array}{l}\text {...Otherwise, they had the } \\
\text { same dark, sepulchral eyes,... } \\
\text { (The City in Crimson Cloak, } \\
\text { p. 115) }\end{array}$ & $\begin{array}{l}\text { Mezar sözcüğü ifade edilirken, } \\
\text { gündelik hayatta sıça kullanılan } \\
\text { grave sözcüğü yerine, arkaik sayılan } \\
\text { ve "ölülere dair" anlamına gelen } \\
\text { sepulchral sözcüğü tercih edilmiştir. }\end{array}$ \\
\hline $\begin{array}{l}\text {...artık gündelik yaşamının tik- } \\
\text { sindirici, sıradan bir ayrıntısıydı } \\
\text { yalnızca.... } \\
\text { (Kırmızı Pelerinli Kent, s. 97) }\end{array}$ & $\begin{array}{l}\text {...had now become nothing } \\
\text { but a common, repulsive } \\
\text { detail of everyday life... } \\
\text { (The City in Crimson Cloak, } \\
\text { p. 115) }\end{array}$ & $\begin{array}{l}\text { Tiksindirici sözcüğünün karşıllğg } 1 \\
\text { olarak, gündelik hayatta çok sık kul- } \\
\text { lanıldığ1 için sıradanlaşan ve etki } \\
\text { düzeyini yitiren disgusting sözcüğü } \\
\text { yerine, pekiştirilmiş bir anlama sahip } \\
\text { olan repulsive sözcüğünün tercih } \\
\text { edildiği görülür. }\end{array}$ \\
\hline
\end{tabular}

Söz konusu sözcüksel tercihler, çevirmenin yazınsal duyarlığına dair ipuçları vermekte ve kadınlık içre bir metinsel kavrayışı ortaya koymaktadır.

İdeoloji ve kültürün kıskacında bulunan çevirmene yeniden yazma görevi biçildiğinden, çeviri süreçleri, çevirmenin kültürel, siyasal, toplumsal arka plan bilgisinden geçerek şekillenir. Her çevirmen aynı metni farklı biçimlerde yazar. Spivak'ın $(1999,12)$ yazınsal çeviri metinleriyle uğraşanları çok kimlikli ve katmanlı bir yazar olarak gören bakış açısıyla gerçekleştirdiği de budur. Spivak'a göre her çeviri yeni bir okuma denemesidir. Toplumsal cinsiyet ve eşitsizlik konularında duyarlığı olan bir kadın çevirmen olan Amy Spangler'in, yazarın o tür bir kaygısı olmasa dahi kaynak metinde şiddet ve ayrımcılık olarak algılanabilecek dilsel öğeleri tarafsızlaştırması toplumsal cinsiyet üzerinden gerçekleşen bir okuma deneyiminden doğan yazma alışkanlığını ortaya koymaktadır. Tarafsızlaştırma kavramı, erek dil bağlamında eşitsizliği, ayrımcıllğ̆, ötekileştirmeyi çağıracak ifade ve öğeler yerine çevirmenin eşitlikçi, tarafsız, ayrımcılıktan uzak ve kapsayıcı ifade ve öğeler seçmesine göndermede bulunur. Kadın çevirmen Amy Spangler, Kırmızı Pelerinli Kent'te bunu pek çok kez yapar:

...porno kasetlerden kamçıya dek, çiftleşme eyleminin gereksinebileceği her türlü araç gereci...

(Kırmızı Pelerinli Kent, s. 113) ...equipment that one might need for the act of copulation, from pianos to saunas, and porn videos to whips,...

(The City in Crimson Cloak, p. 134)
Copulation ifadesi, günümüzde, "eşleşme" anlamina gelen "coupling” sözcügünden türetilmiş bir sözcük olarak kullanılır. Doğrudan “döllenme” olayını çağrıştırabilecek breeding sözcüğü yerine, copulation ifadesinin tercih edilmesi, tarafsızlaştırmanın önemli örneklerinden biri sayılabilir. 
Bilinç ötesine işleyen kültürel norm ve anlayışlar, çevirmenin yeni bir metin yaratırken metnin içerisine alışkanlıkla kendi kimliğinden damıttığı göstergelerde kendisini belli eder. Kimliklerin kavşağında konumlanan çevirmeni çeviriye yakınlaştıran şey de kendi alışkanlık ve deneyimlerini yansitma isteğidir. Kristeva'ya $(1980,58)$ göre, kendisini bir çeşit yazar olarak gören çevirmen için, yazmak, sağaltıcı bir eylem halini alabilir; yazmak eylemi, bu hususta, gerçekçi olmayan bir sınır koyar, keyfi yasalar oluşturur ve kişisel bir sonluluk arz eder. Ancak yazar ve çevirmen arasındaki bir fark vardır: keyfilik, yazarda kitabı istediği yerde sonlandırma halinde kendini gösterirken, çevirmende "öteki" yazar durumuna düşmekle başlayan ve söylemi kişisel alımlama sürecinden geçirerek aktarmakla devam eden bir maceraya dönüşür. Venuti'nin (1995, 20) çevirmenin kimliği ve kimliğin arkasındaki görünmezliği kavramlarıla, çevirmeni iki kültürün arasında bir yere konumlandırmasında da aynı durumla karşılaşılır. Çevirmen hem kaynak kültürün yabancısı olarak hem de erek kültüre dışarıdan bir izleyici olarak saydam bir zeminde seyrini sürdürür. Kadın çevirmen Amy Spangler'in bakış açısıyla birlikte yeniden canlanan kaynak metin öğeleri, yine çevirmenin dışarıdan bir izleyici olarak erek kültüre has bir metin yaratma ve erek okurla ilişki kurma eğilimi üzerinden kendini var ederler. Spangler, kendi kültürel arka planına it sözcükleri çevirinin içine yerleştirir ve erek metne kaynak metinde olmayan kadın-duygusal bir özellik verir.

\begin{tabular}{|c|c|c|}
\hline $\begin{array}{l}\text { sonsuz bir gençlik } \\
\text { bağışlamış bu topraklara. } \\
\text { (Kırmızı Pelerinli Kent, } \\
\text { s. 34) }\end{array}$ & $\begin{array}{l}\text { God bestowed unto these } \\
\text { lands an endless summer. } \\
\text { (The City in Crimson } \\
\text { Cloak, p. 46) }\end{array}$ & $\begin{array}{l}\text { Bağışlamak sözlükte ilk anlamıyla forgive } \\
\text { olarak karşımıza çıkarken, erek metinde } \\
\text { "günahları bağışlamak" anlamına gelen bestow } \\
\text { sözcüğü kullanılmıştır. }\end{array}$ \\
\hline $\begin{array}{l}\text { yırtıcı bir kuş gibi } \\
\text { kendini uçurumlardan } \\
\text { salan arzu... } \\
\text { (Kırmızı Pelerinli Kent, } \\
\text { s. 34) }\end{array}$ & $\begin{array}{l}\text { desire throwing itself off } \\
\text { of cliffs like a rapacious } \\
\text { bird... } \\
\text { (The City in Crimson } \\
\text { Cloak, p. 46) }\end{array}$ & $\begin{array}{l}\text { Yırtıcı kuş anlamında bird of prey gibi } \\
\text { ekolojik bir ifade yerine, "zorbalık" anlamına } \\
\text { da gelen rapacious sözcüğ tercih edilmiştir. }\end{array}$ \\
\hline $\begin{array}{l}\text { Hep doygun ama hep aç. } \\
\text { (Kırmızı Pelerinli Kent, } \\
\text { s. 34) }\end{array}$ & $\begin{array}{l}\text { Always sated, yet always } \\
\text { ravenous... } \\
\text { (The City in Crimson } \\
\text { Cloak, p. 46) }\end{array}$ & $\begin{array}{l}\text { Doygun sözcüğünün karşıllı̆̆ olarak, "suyun } \\
\text { doygunluk seviyesine ulaşması" anlamına } \\
\text { gelen sated sözcüğü kullanılmıştır. Rapacious } \\
\text { sözcüğüyle ahenk oluşturmak için, yaygın } \\
\text { kullanım olan ve "fiziksel açlık" anlamına } \\
\text { gelen hungry sözcüğü yerine, aynı son ekle } \\
\text { biten ve "ruhani açllk" anlamına da gelen } \\
\text { ravenous sözcüğü erek metne yerleşilmiştir. }\end{array}$ \\
\hline
\end{tabular}

Yukarıdaki kararlar incelendiğinde, çevirmenin erek metin bağlamında daha lirik bir söyleyiş yaratma arzusunun, gündelik hayatta çok sık kullanılmayan, yazınsal bağlamda farklı anlamsal değerler içeren sözcüklerin erek metne yerleştirilmesiyle kendini gösterdiği sonucuna varılabilir.

Çevirmen, kaynak metni kendi kültürel arka planından getirdiği kimlik özelliklerinden bağımsız olarak yorumlayamayacağından, çeviri sürecinde en az müdahale olsa da kaynak dilde yaratacağı metin, çevirmenin kimliğinin bir parçasıdır. Gentzler $(2001,34)$ çevirinin kaynak metindeki anlamı aktarmaktan daha önemli bir işlevi olduğunu belirtir: Kültürel devrimler yaratmak. Gentzler'e göre, dillerin sürekli olarak gelişen ve birbiriyle iç içe geçen yapısından ötürü çevirinin doğası da değişmektedir, çeviri süreci ise bir yeniden yazma süreci olarak yabancıyı tanıdık kılma, yabancı kültürün kaleydoskopik algısından süzerek kendi kültürünü görme olarak karşımızda durur. 
Flotow (1997, 86) toplumsal cinsiyet etkeninin ve kadın olmayı öğrenmenin etkisinin neredeyse her toplumda kendini gösterdiğini, hatta bazı toplumlarda alt gruplar arasında dahi bu algıya dair birtakım farklar görmenin mümkün olduğunu belirtir. Flotow, bu bakımdan çeviriyi siyasi çizgi, etnik arka plan, dini inançlar, ekonomik ve ırksal farklar bağlamında kadın hareketini bir arada tutacak ve dayanışma hissini büyütecek bir özel durum olarak yorumlar. Flotow'a göre, çeviri, kadınlara belirli durumlarla başa çıkarken karşılaşacakları zorlukları anlama, algılama ve kadın kültürü içerisinde başka kadınların deneyimleriyle özdeşlik kurma şansını vermiştir. Bunlar ışığında, kadın çevirmen Amy Spangler, kendindeki toplumsal cinsiyet eşitliği algısını besleyen, farklılıklara eşitlikçi yaklaşım sergileyen anlayışıyla kaynak metindeki özgün kültürel öğeleri erek kültür okuruna herhangi bir değişikliğe gerek görmeden yansıtma eğilimi taşımaktadır.

\begin{tabular}{|c|c|c|}
\hline $\begin{array}{l}\text { meraktan yanıp tutuşan } \\
\text { gringa'yı } \\
\text { (Kırmızı Pelerinli Kent, s. 74) }\end{array}$ & $\begin{array}{l}\text { the gringa, burning with curiosity, } \\
\text { (The City in Crimson Cloak, p. 90) }\end{array}$ & $\begin{array}{l}\text { Gringa Latin Amerika'da sokak } \\
\text { dilinde "ziyaretçi olarak gelen } \\
\text { yabancı kadın" anlamına gelir. }\end{array}$ \\
\hline $\begin{array}{l}\text { yoksa ömrü billah favela’ya } \\
\text { adım atmayacak } \\
\text { (Kırmızı Pelerinli Kent, s. 74) }\end{array}$ & $\begin{array}{l}\text { otherwise they would never in this } \\
\text { lifetimeever have set foot in a } \\
\text { favela. } \\
\text { (The City in Crimson Cloak, p. 90) }\end{array}$ & $\begin{array}{l}\text { Favela sözcüğü “yoksul } \\
\text { mahallelerdeki derme çatma } \\
\text { yapılar”'1 ifade eder. }\end{array}$ \\
\hline $\begin{array}{l}\text { dört Carioca'yı Yeraltı } \\
\text { Irmağı'ndan getirmişti. } \\
\text { (Kırmızı Pelerinli Kent, s. 74) }\end{array}$ & $\begin{array}{l}\text { four Cariocas who agreed to go on } \\
\text { this journey } \\
\text { (The City in Crimson Cloak, p. 90) }\end{array}$ & $\begin{array}{l}\text { Kaynak metindeki Carioca } \\
\text { ifadesi, “Brezilya'daki sokak } \\
\text { hayatı”na göndermede } \\
\text { bulunmak için kullanılmıştır. }\end{array}$ \\
\hline
\end{tabular}

Yukarıdaki kararlar ekseninde değerlendirildiğinde, sözcüklerin kaynak metinde olduğu gibi bırakılmasının, metnin hem çok-kültürlü hem de çok-dilli yapısına hizmet ettiği düşüncesini beraberinde getirdiği görülecektir. Kadın çevirmen Amy Spangler, böyle yaparak, kültürleri birleştirir, farklı dillere ait evrenleri yakınlaştırır ve eşitlik algısıyla yabancıya erek metin içerisinde ev sahibi kadar yer açar.

Hermans $(2009,145)$ ise bütün yorumlama süreçlerinin ötesinde, yazar-çevirmenin kişisel poetikasının ürünü olarak edebiyat metinleri çevirisinin yeniden yazmadan ayrılamaz bir süreç olduğunu ve yazar-çevirmenin kendi hayali olan poetikayı yaratmada kaynak metni araçsallaştırdığını öne sürer. Bu bakımdan, kadın çevirmen Amy Spangler, kadın yazarın üslubuyla ve duygu durumuyla özdeşleştirme yoluna giderek, aynı duyarlığ 1 yakalayabilir, belki de kaynak kültürle karşılaştırıldığında erek kültür açısından daha duyumsal bir metin oluşturabilir.

Yaşam, bütün kayıtsızlığı ve alaycılığıyla akıp giderken,

(Kırmızı Pelerinli Kent, s. 65) kişisel bir gözlem kalesi yapmiştır.

(Kırmızı Pelerinli Kent, s. 65)
As life continues flowing by, Alaycılık, "hayatın acımasızlı̆̆ına with all of its indifference and karşı bir direniş"e benzetilerek, irreverence, ironicalness yerine, direniş (The City in Crimson Cloak, p. (resistance) sözcüğünü de çağrıştıran 80) irreverence ile ifade edilmiştir.

he has managed to construct Korkunç sözcüğü horrible ile ifade nothing more than a personal edebilecekken, "fiziksel şiddetten observation tower in the doğan korku" anlamina da gelen gruesome desert of reality. gruesome sözcügü kullanılmıştır.

(The City in Crimson Cloak, p.

80) 
sallantılı, uğultulu bir kule...

(Kırmızı Pelerinli Kent, s. 65)
A brittle, moaning tower,

(The City in Crimson Cloak, p. 80)
Sallant1lı ifadesi, "fiziksel salınım, kıpırdama" anlamina gelen pendant sözcüğü yerine, "duygusal kırgınlık” anlamına da gelen brittle sözcüğü ile yeniden yaratılmıştır.

herkes şu soruyla fazlasıyla bo- everyone who takes up a pen Boğuşmak, "fiziksel mücadele” gönğuşmak zorundadır: must struggle with this reality.

(Kırmızı Pelerinli Kent, s. 65)

(The City in Crimson Cloak, p. 80) dermesi içerse de, çevirmen "mücadele etmek" anlamına gelen struggle with ifadesi kullanılmıştır.

Yukarıdaki kararlar üzerinden bir değerlendirme yapıldığında, kadın çevirmen Amy Spangler'in, şiddetin fiziksel ve duygusal boyutlarına ilişkin farkındalığ olduğu da söylenebilir. Bu hususta, metnin kadın çevirmeni, metnin kadın yazarı ile sıkı bir “kız kardeşlik” bağı kurar.

Bundan sonra, House (2016, 71), çevirmeni küresel söylemlerin kesişim noktasında bir yere oturtur ve çevirmeni bütün kimlik çatışmalarının düğümünü çözecek kişi olarak tarif eder. Munday ve Blakesley $(2016,9)$ ise kültürel aktarım ve değiş tokuşu sağlayan, kültürleri çaprazlayarak melez metinler ortaya çıkaran kişi olarak gördüğü çevirmeni kültürel virajların ortasına yerleştirmiş ve ona toplumları yönlendirmede yaşamsal bir rol biçmiştir. Kadın çevirmen Amy Spangler, toplumsal düzende kadının erkekle eşit olmadığı fikrini aklının bir köşesinde tutarak, ancak yine de kadın olmanın verdiği iç huzurla, yaptığının toplum nezdinde aykırılık sayılabileceğini umursamadan sözcükleri cümlelerinin içerisinde konumlandırır.

dingin ve yalındı okyanus, the ocean was calm and austere, Yalın sözcüğünün karşıllı̆ı olarak erek (Kırmızı Pelerinli Kent, s. (The City in Crimson Cloak, p. metinde tercih edilen austere sözcüğü 114) 136)

"sade, süssüz, zor, güç” gibi yan anlamlar taşır.

Coşkulu bir senfoninin ilk notalar1

(Kırmızı Pelerinli Kent, s. 114) the first notes played by an ecstatic symphony

(The City in Crimson Cloak, p. 136)
Coşkulu sözcüğü, "hissi uyandırmak, harekete geçirmek” gibi erkeklikle ilişkili bir eylem olarak görülebilecek stirring sözcügü yerine, bu anlamdan uzakta, daha tarafsız bir dilsel ifade olan ecstatic sözcüğüyle karşılanmıştır. köhnemiş, tüketilmiş bir düşü yeniden yaratıyordu.

(Kırmızı Pelerinli Kent, s. 114) made a worn-out, diladipated, exhausted dream brand new

(The City in Crimson Cloak, p. 136)
Köhnemiş sözcüğü, gündelik kullanımda ilk anlamı "eskimek, yaşlanmak" olan become old ile ifade edilebilecekken, çevirmen tarafından "harap olmak, bitap düşmek" anlamını da içinde barındıran diladipated sözcüğü tercih edilmiştir.

altın ve erguvan renkli the clouds flashed, glimmering $\quad$ Erguvan sözcüğü, kaynak kültür için parıltılarla yanıp sönüyordu in gold and purple. önem arz etse de, erek kültür okuru için bulutlar.

(Kırmızı Pelerinli Kent, s. $\quad 136)$

(The City in Crimson Cloak, p. 114) aynı önemi arz etmeyebilir. Dolayısıyla erguvan rengini ifade eden purple sözcüğü erek metne yerleştirilmiştir.

uçları alev almış kanatlarını slowly spread its fire-tipped yavaşça açıyordu. wings.

Uçları alev almış ifadesi ele alındığında,

(Kırmızı Pelerinli Kent, s. (The City in Crimson Cloak, p. 114) 136)

“ateş" ve "parmak ucu" anlamına gelen fire ve tip sözcüklerini bir araya getirerek, fire-tipped ifadesinin türetildiği görülür. 
Yukarıdaki sözcük seçimleri incelendiğinde, kadın çevirmen Amy Spangler'in, kaynak metni, yazınsal duyarlık, kadın duyarlığı, kültür duyarlığı, yabancı olanı anlatma gibi açılardan ele aldığı görülecek; yalnızca bir kadın olarak değil, farklı kültürler tarafından yabancı addedilen ve merkezden çevreye doğru itilen bütün "ötekilerin” bir elçisi ve ses vereni olarak iki metnin arasında, üç kültürün ortasında, dillerin anlam evrenlerinin kesiştiği noktada durduğu fark edilecektir.

\section{Sonuç}

Sonuç olarak, yazarın Rio sokaklarında yaptığı yolculuğu bir yarı-gölge olarak takip eden çevirmen, incelediğimiz kısımlarda yazarın kültürüne özgü birtakım kavramları (söylence, alay, kundak, erguvan, bağışlamak vd.) aktarmada kaymalara yol açmaktadır. Çevirmen, kaynak metinde pek aşina olmadığı kavramları kendi dil evrenindeki kavramlarla aktarma yoluna gider. Bazen de anlamı olduğu gibi aktarmaktan ziyade kendi alımlamasına uygun olarak çevirme kararı alır. Bu da bazı durumlarda anlamı daraltır. Buna ek olarak, metnin çevirmeni Amy Spangler'in, yazarın kaynak kültürde anlaşılma düzeyini yakalayıcı ve tamamlayıcı bir dil düzeyi gerçekleştirdiğini de söylemek mümkündür. Bu sayede, erek okurun zihninde yazarın söylemeye çalıştığ şeyler doğru çağrışımlarla yer bulmuş olur. Yazınsal çeviri tarihi boyunca hain olarak addedilen çevirmen olgusu üzerinden düşünüldüğünde, Kırmızı Pelerinli Kent'in çevirmeni Amy Spangler'in, hem kaynak kültüre özgü nitelikleri hem de yazarın romanı konumlandırdığı Rio'ya dair anlatıları başarıyla erek dile aktardığı görülmektedir. Çok-kültürlülük, çok-cinsiyetlilik, çok-dillilik kavramlarının kavşağında yer alan çevirmen, bir yandan Brezilya'yı hayal ederken, diğer yandan da Türkçeyi anlamaya çalışır, dillerin ve kültürlerin dolambaçlı yollarında yaptığı seyahati sonlandırır, mesafeleri aşar. Aslı Erdoğan, kadın bir yazar olarak yalnızca kadınların sorunlarından değil, aynı zamanda bireyin Türkiye toplumu içerisinde verdiği varoluş mücadelesinde cinsellik, bekâret, muhafazakârlık, toplumsal baskılar, yozlaşma, çocukluk, yetişkinlik gibi evrensel değerlerden de bahsetmektedir. Bunu da düz bir dil kurgusundan ziyade, okuru bilinçaltından bilinçdışına yolculuk ettirebilecek alternatif sözcük seçimleri ve dil oyunlarıyla, yabancı kültür ve dillere özgü kavramsal kullanımlarla gerçekleştirir. Kadın çevirmen Amy Spangler, yeniden yazmanın cinsiyet, kültür, dil, din, siyasi düşünce gibi kavramsal yapılarla oluşmuş arka planından yararlanarak, erek okura hem Aslı Erdoğan'dan izler taşıyan hem de kendi dokunuşlarını kattığı bir metin bırakır.

\section{Yazarın Notu}

Sabancı Üniversitesi Sanat ve Sosyal Bilimler Fakültesi ile Toplumsal Cinsiyet ve Kadın Çalı̧̧maları Mükemmeliyet Merkezi tarafindan yedi yıldır düzenlenen "Dicle Koğacıoğlu Makale Ödülü” kapsamında jürinin beğenisini kazanmış ve 24 Aralık 2016 tarihinde gerçekleştirilen öğrenci konferansında sunulmaya değer bulunmuştur. 


\section{KAYNAKÇA}

Armağan B. (2013). Aslı Erdoğan, Hayatı, Edebi Kişiliği, Eserleri. Yayımlanmamış Yüksek Lisans Tezi. Karadeniz Teknik Üniversitesi, Trabzon 2013.

Bağcı S. T. (2010). İzlek Açısından Aslı Erdoğan Anlatıları. Yayımlanmamış Yüksek Lisans Tezi. Fırat Üniversitesi, Elazığ 2010.

Bassnett S. \& Lefevere A. (1998). "Constructing Cultures: Essays On Literary Translation Topics in Translation: 11”. Multilingual Matters Ltd. (1998).

Cumhuriyet (1990). Yunus Nadi Ödülleri 1989 1990. Cumhuriyet. Kaynak: http://www.cumhuriyetarsivi.com/ katalog/4200/sayfa/1990/6/29/10.xhtml

Erdoğan A. (2003). La Ville dont la Cape est Rouge. Çev. Esin Soysal Dauvergne. Acte Sud 2003.

Erdoğan A. (2007). The City in Crimson Cloak. Çev. Amy Spangler. California 2007.

Erdoğan A. (2008). Die Stadt mit der Roten Pelerine. Çev. Angelika Gillitz-Acar, Angelika Hoch. Deutschland 2008.

Erdoğan A. Kırmızı Pelerinli Kent. (1998 - 1999) Adam Yayınları, 1-2. Basım; (2001 - 2005) Türkiye İş Bankası Kültür Yayınları, 3-5. Basım; (2006 - 2012, 6-9. Basım; (2014), 10. Basım.

Forfatterforening (2013). Ord i Grenseland-prisen til Asli Erdogan. Den norske Forfatterforening. Kaynak: http://forfatterforeningen.no/artikkel/ord-i-grenseland-prisen-til-asli-erdogan\#.WSx5KuLTIV

Gentzler E. (2001). Contemporary Translation Theories: Revised (Topics in Translation 21). England 2001.

Hermans T. (2009). Translation in Systems: Descriptive and System-oriented Approaches Explained. England 2009.

House J. (2016). “Translation As Communication Across Cultures”. Across Languages and Cultures 17/2 (2016) 137-142.

İmşir Ş. B. (2012). Aslı Erdoğan'ın Roman ve Öykülerinin Julia Kristeva Teorileri Çerçevesinde İncelenmesi. Yayımlanmamış Yüksek Lisans Tezi. İstanbul Üniversitesi, İstanbul 2012.

Karaca Ş. (2012). “Aslı Erdoğan'ın Taş Bina ve Diğerleri’nde Mekânın Hâlleri”. Türkbilig 24 (2012) 155-170.

Kristeva J. (1980). Desire in Language: A Semiotic Approach to Literature and Art. USA 1980.

Munday J. \& Blakesley J. (2016). "Poetry Translation: Agents, Actors, Networks, Contexts”. Translation and Literature 25/1 (2016) 1-9.

Özger M. \& Parlakpınar M. (2012). “Aslı Erdoğan'ın Anlatılarında Ontolojik Sorunlar”. Turkish Studies: International Periodical for the Languages, Literature and History of Turkish or Turkic 7/4 (2012) 2561-2575.

Payot M. (2014). "Mille et une fictions au Moyen-Orient”. L'express. Kaynak: http://www.lexpress.fr/ culture/livre/mille-et-une-fictions-au-moyen-orient_1633956.html

Savaş N. (2004). “Aslı Erdoğa'nın Norveç Başarısı”. Biamag Cumartesi. Kaynak: http://bianet.org/ biamag/medya/47535-asli-erdoganin-norvec-basarisi

Spivak G. C. (1999). A Critique of Post-Colonial Reason: Toward the History of A Vanishing Present. England 1999.

Svenskapen (2016). "Svenska PENs Tucholskypris 2016 går till Aslı Erdoğan”. Svenskapen. Kaynak: http://www.svenskapen.se/index.php?option=com_k2\&view=item\&id=374:svenska-penstucholskypris-2016-gar-till-asli-erdogan\&Itemid=50

Unionsverlag (2010). “Sait Faik-Preis für Asli Erdogan”. Unionsverlag. Kaynak: http://www.unionsverlag. com/info/text.asp?text_id=3095

Unionsverlag (n.d.). “Ausführliche Biografie von Asli Erdogan (Englisch)”. Unionsverlag. Kaynak: http://www.unionsverlag.com/info/link.asp?link_id=7454\&pers_id=1762

Venuti L. (1995). The Translator's Invisibility: A History of Translation. England 1995.

Verissimo J. (2011). “Norsk Litteraturfestival (24-29 May 2011)”. Awapointe. Kaynak: http://oniammemory. blogspot.com.tr/2011/05/norsk-litteraturfestival-24-29-may-2011.html

Von Flotow L. (1997). Translation and Gender: Translating in the 'Era of Feminism. England 1997.

Writers-in-residence (2012). "In Conversation with Aslı Erdoğan". Writers-in-residence. Kaynak: http://www.writers-in-residence.ch/en/event/8 